\title{
Concentração de potássio na solução nutritiva e a qualidade e número de frutos de melão por planta em hidroponia ${ }^{1}$
}

\author{
Potassium concentration in nutrient solution and quality and number of \\ fruits of melon, cultivated in hidroponic
}

\author{
Caciana Cavalcanti Costa ${ }^{2}$ Arthur Bernardes Cecílio Filho \\ Rodrigo Luiz Cavarianni ${ }^{4}$ José Carlos Barbosa $^{5}$
}

\section{RESUMO}

\begin{abstract}
O experimento foi conduzido em hidroponia (NFT) no período de junho a novembro de 2001, na FCAV-UNESP en Jaboticabal-SP, situada a $21^{\circ} 15^{\prime} 22^{\prime \prime}$ Sul, 48 $18^{\prime} 58^{\prime \prime}$ Oeste, e altitude de 575 metros. O híbrido Bônus no 2 foi cultivado em blocos casualizados, em esquema de parcelas subdivididas, com seis repetições. Os elementos avaliados foram número de frutos por planta (2, 3, 4 e fixação livre) e concentração de potássio na solução nutritiva $\left(66 ; 115,5 ; 165\right.$ e 247,5mg $\left.L^{-1}\right)$. O experimento teve como objetivo avaliar a concentração de potássio na solução nutritiva e número de frutos por planta sobre a qualidade dos frutos do meloeiro. Concentrações maiores do que 66mg $L^{-1}$ de potássio na solução nutritiva não promoveram incrementos nas características de qualidade dos frutos do meloeiro como: teor de sólidos solúveis médio de todos os frutos da planta, do segundo fruto, da acidez total titulável média de todos os frutos da planta, do primeiro fruto, do segundo fruto, do índice de maturação, da espessura da polpa e do índice de formato dos frutos. Frutos oriundos de plantas de melão com dois frutos apresentaram maior teor de sólidos solúveis e acidez total titulável, independente da concentração de potássio na solução nutritiva. O maior número de frutos por planta reduziu a espessura do mesocarpo dos frutos.
\end{abstract}

Palavras-chave: Cucumis melo var reticulatus, hidroponia, cultivo protegido, nutrição de plantas qualidade de frutos.

\section{ABSTRACT}

The experiment was carried out in Jaboticabal-SP. The hybrid Bonus $n^{0} 2$ was cropped in randomized blocks design, in split-plot scheme and six replications. Fruit number per plant $(2,3$,
4 e free fruit set) and potassium concentration in the nutrient solution $\left(66,115.5,165\right.$ and $\left.247.5 \mathrm{mg} \mathrm{L}^{-1}\right)$ were the studied factors. The increase of potassium concentration in the nutrient solution did not promote increase melon fruit quality characteristics such as: average soluble solid content from all plant fruits or that of the second fruit; average total tritratable acidity from all plant fruits and that of the first or second fruit. Also it not affected maturation index (ratio); mesocarp thickness and fruit shape index. Fruits from plants with two fruits presented higher soluble solids content and total tritritable acidity independent of $K$ concentration in nutrient solution. The higher fruit number per plant reduced mesocarp thickness.

Key words: Cucumis melo var. reticulatus, hidroponic, protection cultivated, plant nutrition, fruits quality.

\section{INTRODUÇÃO}

O potássio é considerado o nutriente da qualidade, devido aos seus importantes efeitos nos produtos, pois ele afeta atributos como a cor, tamanho, acidez, resistência ao transporte, manuseio, armazenamento, valor nutritivo e qualidades industriais (RAIJ, 1990).

Nas características relativas dos frutos, o teor de sólidos solúveis, é o critério responsável pelo estabelecimento dos padrões de qualidade nas regulamentações de mercado (GRANGEIRO et al., 1999), que conjuntamente com dos ácidos orgânicos, contribui para a avaliação do flavor do fruto.

\footnotetext{
${ }^{1}$ Trabalho financiado com recursos da Fundação de Amparo à Pesquisa do Estado de São Paulo (FAPESP), processo 2000/01799-2.

${ }^{2}$ Engenheiro Agrônomo, aluno de Pós-graduação em Agronomia, Faculdade de Ciências Agrárias e Veterinárias (FCAV), Universidade Estadual Paulista (UNESP), Jaboticabal, SP, bolsista CNPq.

${ }^{3}$ Engenheiro Agrônomo, Professor Assistente, doutor, Departamento de Produção Vegetal, FCAV, UNESP, Via de acesso Prof. Paulo

Donato Castellane, s/n, 14.884-900, Jaboticabal, SP. E-mail: rutra@fcav.unesp.br. Autor para correspondência.

${ }^{4}$ Aluno de graduação em agronomia, FCAV, UNESP, bolsista FAPESP.

${ }^{5}$ Engenheiro Agrônomo, Professor Titular, Doutor, Departamento de Ciências Exatas, FCAV, UNESP, Jaboticabal, SP.
} 
Vários são os fatores ambientais (temperatura, umidade, luz e vento) e relativos a condução da cultura (semeadura, irrigação, uso de fertilizantes, espaçamento, aspectos fitossanitários, seleção de variedades e práticas relacionadas a colheita) citados por CHITARRA \& CHITARRA (1990), com possibilidades de afetar a qualidade do fruto. O número de frutos por planta e a disponibilidade de potássio para as plantas são dois fatores relativos ao manejo cultural com potencial efeito sobre a qualidade dos frutos de meloeiro, uma vez que podem alterar a razão área foliar por fruto, ou seja, modifica a relação fonte e dreno. MONTEIRO \& MEXIA (1988) observaram que quanto menor a área foliar disponível por fruto, menor foi o teor de sólidos solúveis. Verificaram maior teor de sólidos solúveis em frutos provenientes de plantas conduzidas com um só fruto, e sua redução com o aumento de número de frutos por planta.

MARREIROS \& PAQUETE (1995) informam que, no melão, o potássio afeta a concentração de açúcares e relacionam o nutriente com a maturação e a qualidade do fruto. Também NERSON et al. (1997) verificaram que o potássio aumentou o teor de sólidos solúveis em frutos de melão cv. Gala quando se elevou a concentração do nutriente na solução nutritiva de 100 para $400 \mathrm{mg} \mathrm{L}^{-1}$. Por outro lado, BAR-YOSEF (1997) verificou aumento na concentração de açúcares sem constatar efeito significativo sobre o teor de sólidos solúveis, à medida em que maior foi a concentração de potássio na solução nutritiva. Resultados semelhantes foram obtidos por FARIA et al. (1994) e RODRIGUES et al. (2001) os quais não constataram efeito provável do potássio sobre o teor de sólidos solúveis em frutos de meloeiro cultivado no solo.

O objetivo do trabalho foi avaliar as características qualitativas dos frutos de melão rendilhado, cultivado em hidroponia, em função da concentração de potássio na solução nutritiva e do número de frutos por planta.

\section{MATERIAL E MÉTODOS}

O experimento foi conduzido de 01 de junho a 04 de novembro de 2001, em casa de vegetação, na UNESP, Jaboticabal-SP, situada a $21^{\circ} 15^{\prime}$, 22" S, 48¹8'58" W, e altitude de 575 metros.

O delineamento experimental foi o de blocos casualizados, em esquema de parcelas subdivididas, sendo a concentração de potássio (tratamento principal) e número de frutos (tratamento secundário), com seis repetições. A unidade experimental foi constituída por nove plantas, sendo consideradas úteis para coleta dos dados, oito plantas seqüenciais à primeira, de cada unidade experimental.

$\mathrm{O}$ experimento foi realizado em casa de vegetação do tipo arco com lanternim e pé-direito de $3 \mathrm{~m}$, sem fechamento lateral e frontal, coberta com filme de polietileno de baixa densidade aditivado anti$\mathrm{UV}$, de $150 \mathrm{~mm}$ de espessura. Foi instalada uma tela de sombreamento de 30\%, móvel, à altura do pédireito, a qual era estendida sobre a cultura, quando a temperatura interna da casa de vegetação atingia níveis térmicos superior a $30^{\circ} \mathrm{C}$.

O sistema hidropônico utilizado foi do tipo NFT (Nutrient Film Technique), composto por quatro reservatórios de fibra de vidro de $1500 \mathrm{~L}$, contendo as quatros soluções nutritivas em avaliação (quatro concentrações de potássio). Os canais de cultivo constituíram-se por tubos de polipropileno semicirculares com $15 \mathrm{~cm}$ de diâmetro e $4 \%$ de declividade, a fim de permitir o retorno da solução por gravidade para os reservatórios. Os canais apresentavam aberturas circulares de $5 \mathrm{~cm}$ de diâmetro para a colocação das mudas.

As soluções nutritivas utilizadas tiveram em mg L-1 : $200(\mathrm{~N}) ; 40(\mathrm{P}) ; 150(\mathrm{Ca}) ; 133(\mathrm{Mg}) ; 100(\mathrm{~S})$; 0,3 (B); 2,2 (Fe); 0,6 (Mn); 0,3 (Zn); 0,05 (Cu) e 0,05 (Mo). Os fertilizantes e suas quantidades requeridas na formulação das quatro soluções nutritivas, com suas respectivas condutividades elétricas encontra-se na tabela 1. As condutividades elétricas das soluções nutritivas foram monitoradas diariamente e mantidas entre 90 e $100 \%$ das condutividades elétricas das soluções iniciais. $\mathrm{O}$ pH das soluções foi mantido no intervalo entre 5,5 e 6,5, mediante emprego de ácido sulfúrico $6 \mathrm{~N}$. A solução nutritiva foi trocada inicialmente aos 30 dias após o transplantio das mudas e, posteriormente, a cada 15 dias para diminuir efeitos negativos às plantas, resultantes de desbalanços nutricionais. A circulação intermitente das soluções nutritivas foi controlada por um temporizador, que no período das 7 às 10 horas foi 10' ligado e 20' desligado e 10' desligado e 10' ligado no período subseqüente até $18: 30 \mathrm{~h}$. À noite, foram feitas duas circulações da solução nutritiva com duração de 10 minutos, às $21 \mathrm{~h}$ e 1 hora. A vazão dos canais de distribuição da solução foi de aproximadamente $3 \mathrm{~L} \mathrm{~min}{ }^{-1}$ e a temperatura da solução oscilou entre 20 e $28^{\circ} \mathrm{C}$. A oxigenação da solução foi realizada por derivação do bombeamento da solução aos canais, promovendo o retorno sob pressão ao reservatório, de parte da solução nutritiva bombeada aos canais.

O híbrido Bônus no 2 foi semeado em espuma fenólica com dimensões de 5,0 x 5,0 x 3,8cm, 
Tabela 1 - Quantidades ${ }^{1}$ dos fertilizantes empregados para a obtenção das soluções nutritivas propostas. Faculdade de Ciências Agrárias e Veterinárias, Universidade Estadual Paulista, Jaboticabal, SP, 2001.

\begin{tabular}{|c|c|c|c|c|c|c|c|c|}
\hline \multirow[t]{2}{*}{ Solução } & $\begin{array}{l}\text { Nitrato de } \\
\text { potássio }\end{array}$ & $\begin{array}{l}\text { Sulfato de } \\
\text { potássio }\end{array}$ & $\begin{array}{l}\text { Nitrato de } \\
\text { cálcio }\end{array}$ & $\begin{array}{l}\text { Sulfato de } \\
\text { magnésio }\end{array}$ & $\begin{array}{c}\text { Fosfato } \\
\text { monoamônio }\end{array}$ & $\begin{array}{l}\text { Cloreto de } \\
\text { potássio }\end{array}$ & Magnitra & $\mathrm{CE}$ \\
\hline & \multicolumn{6}{|c|}{$\mathrm{g} 1000 \mathrm{~L}^{-1}$} & $\mathrm{~mL}$ & $\mathrm{dS} \mathrm{m} \mathrm{m}^{-1}$ \\
\hline $\mathrm{K}_{1}$ & 183 & - & 790 & 980 & 182 & - & 434 & 2,42 \\
\hline $\mathrm{K}_{2}$ & 228 & - & 790 & 1020 & 182 & 64 & 380 & 2,60 \\
\hline $\mathrm{K}_{3}$ & - & 320 & 790 & 770 & 182 & 64 & 695 & 2,62 \\
\hline $\mathrm{K}_{4}$ & 183 & 362 & 790 & 980 & 182 & 64 & 434 & 2,96 \\
\hline \multirow{2}{*}{\multicolumn{2}{|c|}{$\begin{array}{c}\text { Micronutrientes } \\
{\text { g } 1000 \mathrm{~L}^{-1}}^{\text {M }}\end{array}$}} & Ácido bórico & $\begin{array}{l}\text { Sulfato de } \\
\text { cobre }\end{array}$ & Ferro & $\begin{array}{l}\text { Sulfato de } \\
\text { manganês }\end{array}$ & \multicolumn{2}{|c|}{ Sulfato de zinco } & $\begin{array}{l}\text { Molibidato de } \\
\text { sódio }\end{array}$ \\
\hline & & 1,70 & 0,21 & Solução $^{2}$ & 2,4 & \multicolumn{2}{|c|}{1,36} & 0,13 \\
\hline
\end{tabular}

${ }^{1}$ Percentagens de nutrientes nos fertilizantes obtidas em FAQUIN et al. (1996) e FURLANI et al (1999); ${ }^{2} 10,80 g$ de cloreto férrico hexahidratado, 14,8g de EDTA e 50m1 de hidróxido de sódio a $0,8 \mathrm{~N}$.

e as mudas foram transplantadas aos 21 dias após a semeadura. O espaçamento utilizado foi de $1,00 \mathrm{~m}$ entre canais por $0,30 \mathrm{~m}$ entre plantas no canal. As plantas foram conduzidas em haste única, tutoradas verticalmente até a altura de $1,80 \mathrm{~m}$. Foram deixados frutos nos ramos secundários a partir do $11^{\underline{0}}$ nó caulinar. Procedeu-se a eliminação dos frutos excedentes ao número pré-estabelecido. A haste principal foi podada aos $25^{\circ}$ nós. As hastes secundárias, mantidas por ocasião do fruto fixado, foram podadas duas folhas após o fruto.

A colheita teve início aos 105 dias após o transplante, e foram realizadas dez colheitas durante um período de 28 dias. Os frutos foram colhidos quando verificado o fechamento completo do rendilhamento e o fendilhamento próximo ao pedúnculo.

Durante o período compreendido entre o início da frutificação e a primeira colheita, a média da temperatura mínima foi de $15,3^{\circ} \mathrm{C}$ (amplitude de 7,4 a $25,7^{\circ} \mathrm{C}$ ) e a máxima de $31^{\circ} \mathrm{C}$ (amplitude de 23,1 a $36^{\circ} \mathrm{C}$ ), obtendo-se média diária de $23^{\circ} \mathrm{C}$.

Os elementos avaliados foram número de frutos por planta: 2, 3, 4 e fixação livre (sem raleio) e concentração de potássio na solução nutritiva: 66; 115,5; 165 e $247,5 \mathrm{mg} \mathrm{L}^{-1}$, correspondendo, respectivamente a 40, 70, 100 e $150 \%$ do potássio da solução nutritiva de CASTELLANE \& ARAÚJO (1994), recomendada para o cultivo de hortaliças em NFT.

Para a análise das características dos frutos, adotou-se o mesmo delineamento experimental utilizado para a obtenção dos frutos. Avaliou-se o teor de sólidos solúveis médio (TSS) dos primeiros frutos, segundos e de todos os frutos colhidos por planta, a acidez total titulável média (ATT) dos primeiros, dos segundos e de todos os frutos colhidos planta, índice de maturação ("ratio"=TSS/ATT), espessura da polpa e índice de formato do fruto (diâmetro longitudinal/ transversal).

Os dados obtidos foram submetidos à análise de variância (BANZATO \& KRONKA, 1995), aplicando-se o teste de Tukey a 5\% de probabilidade de erro para interpretação do fator número de frutos por planta e regressão polinomial para concentração de potássio na solução nutritiva.

\section{RESULTADOS E DISCUSSÃO}

Verificou-se que não houve efeito significativo da interação entre os fatores concentração de potássio e número de frutos por planta sobre o teor de sólidos solúveis médio de todos os frutos da planta (TSSF), sendo esta característica influenciada apenas pelo fator número de frutos por planta isoladamente, onde plantas com dois frutos apresentaram maior teor de sólidos solúveis $\left(12,50^{\circ}\right.$ Brix $)$, tabela 2 . Este resultado tem suporte em relatos dos pesquisadores MONTEIRO \& MEXIA (1988), WELLES \& BUITELAAR (1988), GUSMÃO, (2001) e VILELLA JÚNIOR (2001), os quais afirmam que o teor de sólidos solúveis do fruto é favorecido por maior relação área foliar por fruto. Plantas conduzidas com 2, 3, 4 e com fixação livre de frutos, e que na colheita tiveram 2,$0 ; 2,5 ; 2,7$ e 2,3 frutos por planta, apresentaram relação área foliar por fruto de aproximadamente 3735, 2988, 2717 e $3248 \mathrm{~cm}^{2}$ por planta. Segundo HUBBARD et al. (1990), o acúmulo de açúcares é fortemente dependente da área foliar.

Os TSSF observados classificam os frutos colhidos como de boa qualidade, pois encontram-se 
Tabela 2 - Teor médio de sólidos solúveis dos frutos colhidos (TSSF), do segundo fruto (TSSSF); acidez total titulável dos frutos (ATTF), do primeiro (ATTPF) e do segundo fruto (ATTSF) de melão híbrido Bônus, cultivado em hidroponia, em função do número de frutos por planta. Jaboticabal-SP, FCAV-UNESP, 2001.

\begin{tabular}{|c|c|c|c|c|c|}
\hline Número de & TSSF & TSSSF & ATTF & ATTPF & ATTSF \\
\hline frutos/planta & \multicolumn{2}{|c|}{${ }^{o}$ Brix } & \multicolumn{3}{|c|}{ g de ácido citríco por $100 \mathrm{ml}$ de suco } \\
\hline 2 & $12,50 \mathrm{a}^{*}$ & $12,46 \mathrm{a}$ & 0,163 a & $0,159 \mathrm{ab}$ & $0,167 \mathrm{a}$ \\
\hline 3 & $11,96 \mathrm{~b}$ & $11,89 \mathrm{a}$ & $0,153 \mathrm{ab}$ & $0,159 \mathrm{ab}$ & $0,147 \mathrm{a}$ \\
\hline 4 & $12,04 \mathrm{ab}$ & $12,23 \mathrm{a}$ & $0,158 \mathrm{ab}$ & $0,169 \mathrm{a}$ & $0,150 \mathrm{a}$ \\
\hline Livre & $11,83 \mathrm{~b}$ & $11,81 \mathrm{a}$ & $0,149 \mathrm{~b}$ & $0,147 \quad b$ & $0,155 \mathrm{a}$ \\
\hline C.V. $(\%)$ & 5,29 & 7,67 & 14,40 & 15,98 & 15,48 \\
\hline Média Geral & 12,12 & 12,09 & 0,154 & 0,158 & 0,155 \\
\hline
\end{tabular}

* médias na mesma coluna, seguidas por letras diferenttes, diferem a $5 \%$ de probabilidade de erro pelo Teste de Tukey.

muito próximos ou dentro da faixa de 12 a $15^{\circ}$ Brix, considerados por McCREIGHT et al. (1993), para frutos de alta qualidade.

Para o teor de sólidos solúveis do primeiro fruto (TSSPF), somente verificou-se influência da concentração de $K$ na solução nutritiva sobre o primeiro fruto de plantas conduzidas com 3 frutos. Entretanto, não houve ajuste da equação, observandose média de $12,15^{\circ}$ Brix. Para os frutos de plantas conduzidas com 2 , 4 e fixação livre, o TSSPF foi de 12,$55 ; 12,11$ e $12,05^{\circ}$ Brix, repectivamente.

No segundo fruto, não houve efeito significativo dos fatores avaliados. No entanto, a tendência observada segue a mesma para o teor de sólidos solúveis médio dos frutos, onde frutos provenientes de plantas conduzidas com dois frutos apresentaram maior teor de sólidos solúveis (Tabela 2), concordando com MONTEIRO \& MEXIA (1988), os quais observaram maior teor de sólidos solúveis em frutos colhidos de plantas com menor número de frutos.

Houve efeito isolado apenas do fator número de frutos por planta sobre a acidez total titulável dos frutos colhidos em uma planta, e na acidez total titulável do primeiro fruto, não sendo constatada diferença entre os valores de acidez nos segundos frutos da planta. Os resultados observados discordam dos obtidos por EUZÉBIO FILHO (2000), o qual observou efeito positivo do potássio aplicado ao solo sobre a acidez total titulável dos frutos de melão, cv. Bônus nํ-2.

O maior valor encontrado $(0,163 \mathrm{~g}$ de ácido cítrico por $100 \mathrm{~m} 1$ de suco), foi referente ao tratamento com dois frutos (Tabela 2). Os valores encontrados de ATTF estão de acordo com as quantidades de ácido cítrico observadas em melões, que segundo
MENDLINGER \& PASTENAK (1992) variam de 0,05 a $0,35 \mathrm{~g}$ do ácido cítrico por $100 \mathrm{~m} 1$ de suco. PÁDUA (2001), cultivando o melão Bônus $\mathrm{n}^{0} \mathrm{e}$ em solo e hidroponia, verificou ATT de $0,12 \%$ e $0,18 \%$ respectivamente.

A acidez total titulável do primeiro fruto foi menor em frutos colhidos em plantas com fixação livre de frutos em relação a frutos de plantas conduzidas com quatro frutos.

$O$ índice de maturação do fruto não foi influenciado pelos fatores e suas interações. O resultado obtido indica que as variações percebidas em acidez total titulável e teor de sólidos solúveis dos frutos não ocorreram de maneira tão acentuada que promovessem alterações significativas no sabor dos frutos. A média dos valores observados foi de 79 (76,8 a 81,7$)$ muito próximo à média de 80,5 para híbridos de melão rendilhado, avaliados por FACTOR (2000).

Verificou-se efeito do fator número de frutos sobre a espessura do mesocarpo, sendo esta menor $(2,76,2,63,2,57$ e 2,53) à medida que maior foi o número de frutos por planta $(2,3,4$ e fixação livre de frutos). A maior espessura de mesocarpo encontrado em frutos de plantas conduzidas com dois frutos foi superior ao valor encontrado para o híbrido Bônus $\mathrm{n}^{\mathbf{0}} 2(2,37 \mathrm{~cm})$ por PÁDUA (2001) em cultivo hidropônico, e menor que a variação $(2,89-3,00 \mathrm{~cm})$ obtida por MARUYAMA (2000) para os híbridos Bônus $\mathrm{n}^{0} 2$ e Don Carlos.

$\mathrm{O}$ formato de fruto não foi alterado sendo a amplitude do índice em função da concentração de potássio foi de 0,99 a 1,0 e em função do número de frutos por planta, de 0,99 a 1,01; o que atribui aos frutos o formato esférico. VILLELA JÚNIOR (2001) com índice de 1,05 e PÁDUA (2001) obtendo 1,14 no 
verão e 1,19 no inverno observaram tendência de formato oblongo para o híbrido Bônus $\mathrm{n} \stackrel{0}{2}$.

Certamente, outros fatores estão aliados à expressão do formato de fruto que sobrepõe às características avaliadas. Por exemplo, o início do rendilhamento do fruto a ser definido por um estresse fisiológico percebido pela planta, interfere no período de fornecimento de fotossintatos aos frutos, afetando o tamanho e possivelmente seu formato. A este estímulo, podem estar associados a densidade de plantio, luminosidade, temperatura, disponibilidade hídrica, fator nutricional, salinidade, entre outros fatores.

\section{CONCLUSÕES}

A concentração de potássio na solução nutritiva acima de $66 \mathrm{mg} \mathrm{L}^{-1}$ não promoveu incremento no teor de sólidos solúveis de todos os frutos da planta, do segundo fruto, da acidez total titulável de todos os frutos da planta, do primeiro fruto, do segundo fruto, do índice de maturação, da espessura da polpa e do índice de formato dos frutos de melão Bonus $\mathrm{n}^{\circ} 2$.

Frutos provenientes de plantas de melão conduzidas com dois frutos apresentaram maior teor de sólidos solúveis, acidez total titulável e espessura do mesocarpo, em relação a frutos oriundos de plantas com maior número de frutos.

\section{REFERÊNCIAS BIBLIOGRÁFICAS}

BANZATTO, D.A.; KRONKA, S. do N. Experimentação agrícola. 3.ed. Jaboticabal : FUNEP, 1995. 247p.

BAR-YOSEF, B. Greenhouse muskmelon response to $\mathrm{K}$ concentration in water and irrigation. In: INTERNATIONAL CONGRESS ON SOILLES CULTURE, 9., 1997, Jersey. Poceedings... Wageningen : ISOSC, 1997. p.35-50.

CASTEllane, P.D.; ARAÚJO, J.A.C. Cultivo sem solo: hidroponia. 4.ed. Jaboticabal : FUNEP, 1994. 43p.

CHITARRA, M.I.F.; CHITARRA, A. . Pós-colheita de frutos e hortaliças: fisiologia e manuseio. Lavras : ESAL, 1990. 320p.

EUZÉBIO FILHO, O. Calagem, adubação nitrogenada, fosfatada e potássica para melão rendilhado: curvas de resposta. 2000. 62f. Dissertação (Mestrado em Agronomia) - Faculdade de Ciências Agrárias e Veterinárias, Universidade Estadual Paulista.

FACTOR, T.L. Comportamento do meloeiro em cultivo protegido, sob dois tipos de coberturas. 2000. 77f. Monografia (Graduação em Agronomia) - Faculdade de Ciências Agrárias e Veterinárias, Universidade Estadual Paulista.

FAQUIN, V.; FURTINI NETO, A.E.; VILELA, L.A.A. Produção de alface em hidroponia. Lavras, MG : UFLA, 1996. 50p.
FARIA, C.M.B.; PEREIRA, J.R.; POSSÍDEO, E.L. Adubação orgânica e mineral na cultura do melão em um Vertissolo do Submédio São Francisco. Pesquisa Agropecuária Brasileira, Brasília, v.29, n.2, p.183-190, 1994.

FURLANI, P.R. et al. Nutrição mineral de hortaliças, preparo e manejo de soluções nutritivas. In: OLIVEIRA, V. R.; SEDIYAMA, M.A.N (Coord.). Cultivo protegido de hortaliças em solo e hidroponia. Informe Agropecuário, Belo Horizonte, v.20, n.200201, p.90-98, 1999.

GRANGEIRO, L.C. et al. Qualidade de híbridos de melão amarelo em diferentes densidades de plantio. Horticultura Brasileira, v.17, n.2, p.110-113, 1999

GUSMÃO, S.A.L. Interação genótipo $x$ ambiente em híbridos de melão rendilhado (Cucumis melo var. reticulatus Naud.). 2001. 143f. Tese (Doutorado em Agronomia) Faculdade de Ciências Agrárias e Veterinárias, Universidade Estadual Paulista.

HUBBARD, N.L.; PHARR, D.M.; HUBER, S.C. Sucrose metabolism in ripening muskmelon fruit as affected by leaf area. Journal of the American Society for Horticultural Science, v.115, n.5, p.798-802, 1990.

MARREIROS, A.J.C.; PAQUETE, B.C. A cultura do melão (estufa). Ministério da Agricultura, Secretaria do Estado da Agricultura/Direção Regional de Agricultura do Algarve, 1995. 30p. (Guia do extensionista).

MARUYAMA, W.I. Condução de melão rendilhado sob cultivo protegido. 2000. 54f. Dissertação (Mestrado em Agronomia) Faculdade de Ciências Agrárias e Veterinárias, Universidade Estadual Paulista.

McCREIGHT, H.S.; NERSON, H.; GRUMET, R. Melon. In KALOO, G.; BERGH, B.O. Genetic improvement of vegetable crops. Oxfor : Pergamon, 1993. p.267-294.

MENDLINGER, S.; PASTENAK, D. Effect of time, salination of flowering, yield and quality factors in melon, Cucumis melo L. Journal of the American Society for Horticultural Science, v.67, n.4, p.529-534, 1992.

MONTEIRO, A.A.; MEXIA, J.T. Influência da poda e do número de frutos por planta na qualidade dos frutos e produtividade do melão. Horticultura Brasileira, Brasília, v.6, n.1. p.9-12, 1988.

NERSON, H. et al. Monopotassium phosphate as a phosphorus and potassium source for greenhouse-winter-grown cucumber and muskmelon. Journal of Nutrition, Bethesda, v.20, n.2-3, p.335344, 1997.

PÁDUA, J.G. de. Cultivo protegido de melão rendilhado, em duas épocas de plantio. 2001. 108f. Tese (Doutorado em Agronomia) - Faculdade de Ciências Agrárias e Veterinárias, Universidade Estadual Paulista.

RAIJ, van B. Potássio: necessidade e uso na agricultura moderna. Piracicaba : Associação Brasileira para Pesquisa da Potassa e do Fosfato, 1990. 45p.

RODRIGUES, V.L.S. et al. Efeito de doses de nitrogênio e de potássio sobre a qualidade do melão. Horticultura Brasileira, Brasília, 2001. V.19, CD-ROM. 
USHERWOOD, N.R. The role of potassium in crop quality. In: MUNSON, R.D. Potassium in agriculture. Madison : ASACSSA-SSSA, 1985. p.490-514.

VILLELA JÚNIOR, L.E.V. Cultivo de melão em hidroponia com a utilização de efluente de biodigestor. 2001. $116 \mathrm{f}$.
Dissertação (Mestrado em Agronomia) - Faculdade de Ciências Agrárias e Veterinárias, Universidade Estadual Paulista.

WELLES, G.W.H.; BUITELAAR, K. Factors affecting soluble solids content of muskmelon (Cucumis melo L.). Nethrlands Journal of Agricultural Science, v.36, p.239-246, 1988. 